\title{
O CAMINHO DO PEABIRU
}

\author{
Rosangela Melatti ${ }^{1}$ \\ Bárbara Madalena Heck
}

\section{Ressumo}

O Caminho do Peabiru foi a mais importante via transcontinental da América do Sul précolombiana,tinha cerca de três mil quilômetros, ligando o Atlântico ao Pacífico, ou seja, ia do Brasil ao Peru ou vice-versa. Unia o litoral de Santa Catarina e São Paulo ao litoral peruano. No trajeto, o Brasil (Santa Catarina, Paraná, São Paulo, Mato Grosso do Sul), Paraguai, Bolivia e Peru. O Peabiru possibilitou aos exploradores europeus diversas expedições em busca de riquezas em território americano.

Palavras-chave: Aleixo. Incas. Peabiru.

\section{INTRODUÇÃO}

Muitos eram os caminhos utilizados pelos povos sul-americanos antes do Brasil ser colonizado pelos europeus. Um dos mais conhecidos e discutidos pelos historiadores e arqueólogos é o Caminho do Peabiru, que ligava o Brasil até os Andes. A trilha se estendia por aproximadamente três mil quilômetros, sendo que o tronco principal do Caminho do Peabiru cruzava o estado do Paraná de Leste a Oeste, penetrava no Chaco paraguaio, atravessava a Bolívia, a Cordilheira dos Andes e terminava no sul do Peru, onde pegava parte da costa do Pacífico.

A grande importância histórica do Caminho do Peabiru foi primeiramente guiar as migrações indígenas, mas também serviu para facilitar a circulação de mercadorias, o comércio e as missões religiosas, além da penetração dos europeus em território brasileiro.

Este estudo procurou focar em um dos ramais de acesso ao Caminho do Peabiru, haja vista, diversas teorias sobre os principais acessos do referido caminho na região sul do Brasil. Procuramos analisar estudos na região do Vale do Itapocu, especificamente abordando o acesso feito através do rio Itapocu, que corta o município de Jaraguá do Sul.

\section{ALEIXO GARCIA}

\footnotetext{
${ }^{1}$ Graduada em História . E-mail: rosangela_led@hotmail.com

${ }^{2}$ Especialista em Direito. E-mail: barbara.madalena@gmail.com
} 
Em 1512, Fernando, o Católico, rei da Espanha, manda chamar secretamente, um alto funcionário do reino. Juan Diaz de Solís, piloto-mor da marinha castelhana. O rei da Espanha deu a Solís a importantíssima missão de encontrar uma passagem marítima para o Oriente, grande abastecedouro de mercadorias, através do sul da América recém-descoberta. Mas não desejava que Portugal tomasse conhecimento disso, pois a concorrência entre as coroas espanhola e portuguesa era feroz.

Cercada de mistério, a incumbência dada por Fernando, o Católico, foi cumprida por seu funcionário. No próprio ano de 1512, Juan Diaz de Solís teria chegado ao sul do Atlântico. E teria descoberto aquele que, anos mais tarde, seria chamado de Rio da Prata.

Solís recebeu quatro mil ducados e três embarcações tripuladas por cerca de 60 homens. Um desses tripulantes era um obscuro marinheiro português chamado Aleixo Garcia, que mais tarde se integraria à História do Estado de Santa Catarina. Assumindo também na História da América uma importância comparável à de HernánCortéz (conquistador do México) e Francisco Pizarro (conquistador do Peru).

Ao zarpar em 8 de outubro de 1515 do Porto de Lepe, a frota daria início, na verdade, a uma aventura trágica que levaria o próprio Solís a morte. Os detalhes dessa desastrada expedição nunca puderam ser totalmente levantados, pois os diários de bordo foram perdidos.

Rumando de volta à Espanha, após o fracasso na região do Prata, duas das três embarcações da expedição chegaram à Ilha de Santa Catarina. A terceira, onde estava Aleixo Garcia, por algum motivo se atrasara e os outros navegantes decidiram não esperá-la. Prosseguiram viagem. Era abril de 1516. A provável galé atrasada, proveniente do sul, tentou penetrar na barra meridional da Ilha, mas não conseguiu. Colhida talvez por uma tempestade, a embarcação sucumbiu, atirando seus 18 desesperados tripulantes, entre eles, Aleixo, ao mar revolto. Depois de serem recolhidos pelos indígenas, esses marinheiros, marcados pela sorte, viriam a ser os primeiros habitantes europeus de toda Santa Catarina.

A Ilha de Santa Catarina e a costa próxima eram lugares de natureza dadivosa. Peixes, mariscos, patos, veados, antas, perdizes, inhame, mandioca, palmito, mel. Seus donos eram os amáveis Cariós - estes foram designados "Carijós", mais tarde, pelos paulistas escravizadores de índios. Dentre os grupos tupi-guaranis existentes no Brasil e no Paraguai na época dos descobrimentos, os Cariós eram os guaranis mais adiantados. Os Cariós receberam muito bem os sobreviventes do naufrágio e lhes garantiram a subsistência. Supõe-se que Aleixo e os demais náufragos tenham convivido com os indígenas da Ilha, sendo que Aleixo logo se destacou na relação cotidiana com os indígenas, obtendo a sua admiração. Aleixo casou-se com uma índia Carió local e é quase certo que dela tenha tido um filho, nascido em Santa Catarina, que recebeu o nome de Aleixo Garcia Filho.

Não se sabe em que época aconteceu. Pode ter sido em 1521 ou 1522, quando Aleixo já completava cinco ou seis anos de morada nos arredores da Ilha de Santa Catarina. O que se sabe é que, num certo dia, os índios Cariós revelaram ao português seu maior e mais precioso segredo: conheciam um caminho sagrado que levava à uma terra longínqua a oeste, com montanhas altas, onde havia muitos objetos que brilhavam, onde o povo usava roupas e havia um rei de pele mais clara que a deles. Para provar o que diziam, mostraram a Aleixo 
algumas coisas brilhantes que obtiveram daquele povo. Eram peças de prata, prata legítima, constatou o português.

Aleixo Garcia, deslumbrado com as narrativas dos Cariós, começou a organizar sua ousada expedição aos Andes. A impressionante caravana de Aleixo Garcia ficou pronta para partir provavelmente em 1522. Assegurada a vital colaboração dos Cariós, que conheciam perfeitamente o caminho. Com todos os preparativos concluídos, a peculiar expedição partiu para percorrer o caminho sagrado dos guaranis, rumo a rica civilização das montanhas do oeste. Seria a primeira vez que homens brancos trilhariam essa notável via possivelmente milenar.

O caminho, denominado Peabiru, tinha mais de três mil quilômetros e foi a mais importante estrada transcontinental pré-colombiana da América do Sul.

\footnotetext{
"Chamavam os índios Peabiru a um caminho pré-colombianoque se estendia por mais de 200 léguas, por onde os povos indígenas se comunicavam com o mar e com as regiões mais distantes do ocidente. Ao poente do Paraná, o caminho prosseguia, atingindo o Peru e a costa do Pacífico". (p. 73)
}

Descrito como tendo oito palmos de largura e 40 centímetros de profundidade, seria - em boa parte do percurso - forrado por duas ou três espécies de gramíneas, cujos brotos se propagavam com suma facilidade. Diversos autores presumem que o Peabiru era considerado um caminho sagrado porque, através dele, os guaranis paraguaios tentavam chegar a "Terra Sem Mal", que ficaria no Atlântico.

\section{A DESCOBERTA DOS INCAS}

A inusitada caravana com destino ao El Dorado, formada por Aleixo Garcia, seus quatro companheiros náufragos (os outros não quiseram acompanhar) e uma multidão de indígenas Cariós, com suas mulheres e crianças, que segundo historiadores paraguaios, foi de 400 pessoas quando partiu da Ilha de Santa Catarina. A tropa foi multiplicada, ao chegar o Paraguai, somando um total impressionante de 2 mil pessoas.

A presença de mulheres e crianças Cariós pôde ser deduzida por um fato ocorrido muitos anos depois, quando em 1540, o governador do Paraguai, Alvar Nuñes Cabeza de Vaca, tentando seguir as pegadas de Aleixo Garcia rumo às riquezas do Peru,deparou-se, no Paraguai, com um grupo de guaranis que afirmava não se recordar do caminho de Aleixo ao oeste porque "eram muito pequenos quando eles e seus parentes penetraram terra adentro em busca dos índios que possuíam ouro e prata" (p. 91)

A expedição de Aleixo Garcia, saindo de Meiembipe através do caminho do Peabiru, dirigiu-se ao litoral norte de Santa Catarina, chegando à altura da atual cidade catarinense de Barra Velha e penetrando no interior pelo rio Itapocu - o local exato, a foz do Itapocu, pertence hoje ao citado município litorâneo.

A caravana de Aleixo teria chegado primeiramente até as redondezas da atual 
Cochabamba e depois baixado ao sul, até as proximidades de Potosí, a Serra de Prata. Todo esse trajeto possivelmente foi feito por trilhas incas, que se ligavam ao Peabiru. Na sua incursão à cordilheira andina, Aleixo Garcia - sem o saber - chegou muito perto do fabuloso cerro de Potosí, a maior concentração de prata do mundo. Foi nessa região, próxima a Potosí, que Aleixo foi flagrado pelos incas, tendo que fugir. Sem condições de fazer o retorno pelo Caminho do Peabiru, que estava cercado pelos incas, tomou uma rota diferente, talvez pelo rio Pilcomayo, que nasce ao sul de Potosí, flui na direção leste (atual fronteira argentina-paraguaia) e deságua no rio Paraguai, nas proximidades da atual Assunção.

O deslocamento era dificultado pelo tesouro que carregavam. Embora não haja informação precisa sobre o volume dessas riquezas, pode-se deduzir que não era pequeno, baseando-se em dois indícios: uma "amostra" do tesouro, mandada por Aleixo Garcia à Ilha de Santa Catarina, foi estimada em 44 quilos de prata, ouro e outros metais. É de se imaginar, portanto, que a carga principal fosse muitíssimo maior. $\mathrm{O}$ segundo indício aparece na obra "Comentários" de Alvar Nuñes Cabeza de Vaca. Na década de 1540, Cabeza de Vaca esteve no Itatim (Paraguai) e um índio lhe contou que os "Paiaguás", tribo daquela região, tinham em seu poder 63 cargas de ouro e prata em lâminas, braceletes, coroas e outros objetos pequenos, como machadinhas, que foram tirados "de uns espanhóis".

Além do peso dos metais e dos ataques sofridos, outro fator que fez o retorno de Aleixo tornar-se lento e difícil foi o alto número de pessoas que integravam a expedição. Logo depois de cruzar o rio Paraguai, Aleixo decidiu mandar uma amostra de seu tesouro, acompanhada de cartas para os náufragos que haviam permanecido em Santa Catarina, pois se recusaram a acompanhar Aleixo na expedição. Após ter despachado as cartas e a carga de metal, Aleixo e seus expedicionários, por alguma razão, caminharam algumas léguas ao norte, e território paraguaio, até o rio Ipané, e aí montaram acampamento.

Provavelmente, o objetivo de Aleixo Garcia, ao não retornar a Santa Catarina, permanecendo no Paraguai, teria sido o de efetivar uma nova ofensiva às enormes riquezas que encontrara no império Inca. O que não se sabe é se, nas cartas que escreveu, ele insistia em realizar a nova expedição como um projeto pessoal, apenas com a ajuda dos náufragos e dos índios que esses arrebanhassem em Santa Catarina. Ou se tentaria agora dar um caráter oficial á sua empreitada, obtendo apoio da coroa espanhola ou portuguesa.

No acampamento, em Ipané, Aleixo ficou aguardando uma resposta. Não se sabe quanto tempo ficou naquele local. De qualquer modo, numa determinada noite, o acampamento sofreu um ataque. E Aleixo Garcia foi morto. Ou melhor, ele teria sido abatido e comido durante um ato cerimonioso. No que se refere aos acompanhantes índios de Aleixo, seu destino também não foi dos melhores:

Tudo se perdeu. A vida do líder, a expedição e o tesouro. Esse final trágico de uma das mais fantásticas epopeias americanas não impediu, porém, que Aleixo Garcia viesse a ser reconhecido pela História do Paraguai, Bolívia, Argentina e Peru como o mais impetuoso explorador de todo o continente sul-americano, ao contrário do que sucede no Brasil, onde é quase um desconhecido.

Tido como descobridor do Paraguai, onde está nos livros e currículos escolares, assim como Pedro Álvares Cabral está nos nossos, e onde avenidas, ruas e praças foram 
batizadas com seu nome, Aleixo Garcia "abriu a porta" para que outros europeus, atraídos pela sua história e seu fabuloso tesouro encontrado no "El Dorado", viessem a procura do Caminho do Peabiru.

\section{DESBRAVADORES NO CAMINHO DO PEABIRU}

\subsection{CABEZA DE VACA}

O que sempre esteve por trás de toda a história da conquista e colonização do Rio da Prata, eram as riquezas do Peru, ainda que naquela época, elas fossem pouco mais do que uma miragem, pois nada se sabia de efetivo sobre o império Inca. Os sobreviventes das expedições que voltaram para a Europa trouxeram notícias a respeito da Serra da Prata e do misterioso rei branco que a controlava. E da marcha épica de Aleixo Garcia, integrante da armada de Solís, trucidado pelos índios em 1524, quando já empreendia a viagem de volta da extraordinária caminhada aos Andes, e que Aleixo Garcia tinha conseguido enviar à Santa Catarina mensageiros com peças e amostras de ouro e prata.

Há muita polêmica em torno da data e do local de nascimento de Álvar Nuñes Cabeza de Vaca. O mais provável é que tenha se dado em Jerez de La Frontera (Espanha), no primeiro semestre de 1492. Era filho de Francisco de Vera e de Teresa Cabeza de Vaca. Seu avô paterno, Pedro de Vera, morto em 1500, foi o conquistador das Ilhas Canárias e um dos heróis da reconquista de Granada. O sobrenome mais nobre, porém, era herança de dona Teresa e fora concedido à família dela em 1512, quando um certo Martin Alhaja descobriu uma estreita passagem entre as escarpas rochosas da Serra Nevada e a assinalou com o crânio de uma vaca. Por esta passagem cruzaram os exércitos dos reis de Castela, Aragon e Navarro para vencerem a importante batalha de Navas de Tolosa, em 12 de junho de 1212 . Agradecidos, os soberanos concederam ao camponês o título de nobreza que mudaria definitivamente o nome da família.

O primeiro documento que o adelantado Cabeza de Vaca retrata sobre a viagem que fez com sua expedição de 250 homens desde a ilha de Santa Catarina até a Assunção no Paraguai em 1541 é retratado na "Información de lo sucedido a Alvar Núñez, hasta llegar al puerto de la Asunción" de 07 de maio de 1543.

Neste documento, Cabeza de Vaca faz referência em relação ao rio Itapocu, chamando diferentemente por três palavras em sete menções: Ytabucu, Itabucu e Ytalucu. Ao se referir a foz do rio, preferiu chamá-lo de "Baía" (por causa da atual lagoa de Barra Velha onde o rio Itapocu deságua antes de chegar ao mar). No dia 21 de outubro de 1541, Cabeza de Vaca tomou posse da foz do rio Itapocu em nome de sua majestade, dando o nome de "Vera de Ytabucu".

No livro De Hernando Sanabria "Ñuflo de Chaves, El Caballero Andante de la Selva", diz:

“Alvar Nuñez opta por la navegacion del Itabucu. Embarcárcase em la não capitana com lo más de la gente, enfilando proa hacia el 
mentado rio, en tanto que outra fraccion se dirige por tierra almismo sítio. Tras de breve jornada llega a la boca de aquel rio, que los brasileños de ogaño llaman Itapocuy senalan como "correntoso e encaichoeirado".(p. 43).

O Vale do Itapocu tornou-se a via natural mais adequada para os europeus subirem a Serra do Mar. Por semelhantes razões era seu curso e sua foz chamativos naturais, caminhos que demandavam com segurança do litoral ao planalto e deste para aquele, facilitando suas rotas migratórias. E também na busca guaranítica de uma“Terra Sem Mal”, o Vale do Itapocu e todo o litoral catarinense desempenharam um importantíssimo papel.

O Peabiru do ramal do Itapocu ainda era utilizado pelos desbravadores da coroa espanhola no final do século XVI como uma via de comunicação muitos anos depois das expedições de Aleixo Garcia, Cabeza de Vaca e Sanabria que entraram pelo interior do continente pelo rio.

Assim é que, antes e depois da descoberta do Brasil, o Vale do Itapocu era um caminho importante. Dele se valeram os lusos, os espanhóis e outros, para entrarem para o sertão ou dele saírem. E tanto isso preocupou a Coroa lusa, que o Governador Geral Tomé de Souza trancou o caminho, proibindo o seu uso sob pena de morte, ameaça que, naquele tempo, era gravíssima e o trono o cumpria fielmente.

\subsection{MENCIA DE CALDERÓN E OUTROS}

"Dona Mencia Calderón", esposa de "Juan de Sanábria”, que viajava com suas três filhas rumo á Ilha de Santa Catarina. Ela tomou as rédeas da expedição após a morte de seu marido. Depois da infrutífera tentativa de povoar São Francisco do Sul, resolveu seguir por terra até o Paraguai, dando continuidade ao projeto do finado marido, que ambicionava substituir Domingo de Irala, que havia usurpado o poder em Assunção, a audaciosa mulher também iniciou por Barra Velha, a malfadada expedição. Segundo o historiador "Lucas Boiteux":

\footnotetext{
"A travessia foi sobremaneira penosa. Embarcaram às mulheres e crianças em balsas e canoas, com suficiente escolta e subiram pelo "Rio Itaburu" (Itapocu), marchando o resto por terra, seguindo o caminho de "Cabeza de Vaca", com ordens de se reuniram sempre à noite. "Constava em Assunção, a vinte de março de 1556 que "Dona Mencia” e seus acompanhantes haviam chegado à Guaíra”. (p. 171)
}

Depois de "Dona Mencia" outro espanhol, Ruy Diaz Melgarejo aqui esteve em 1555, para alcançar "Ontiveiros" no Paraguai. Melgarejo retornava da viajem que fez de Ontiveiros até São Vicente, voltando pelo mesmo roteiro de Cabeza de Vaca.

Além desses intrépidos exploradores ainda em meados do século XVII, o Rio Itapocú foi trilhado por "Padres Jesuítas", no trabalho de catequese do Gentio e por "Paulistas e Vicentistas" em suas expedições de "apresamento" e mineração. 


\section{A ROTA DO CAMINHO DO PEABIRU}

O caminho, segundo Bond (2004), construído pelos índios sulamericanos,começavaem São Vicente ou Cananéia, no litoral paulista, cruzava o Estado do Paraná de Leste a Oeste,penetrava no chaco paraguaio, atravessava a Bolívia, ultrapassava a Cordilheira dos Andes e alcançava, finalmente, o sul do Peru e a costa do Pacífico. Este era o chamado tronco principal, mas havia vários ramais. Um deles cruzava o rio Paranapanema, na divisa entre São Paulo e Paraná, e baixava para o sul, quase em linha reta, passando pelas atuais cidades paranaenses de Peabiru e Campo Mourão. Outro ramal levava ao litoral de Santa Catarina; e outro, ainda, provavelmente, ao Rio Grande do Sul.

\footnotetext{
"O caminho se caracterizava por apresentar cercade 1,40 m de largura e leito com rebaixamento médio em relação ao nível do solo de cerca de $40 \mathrm{~cm}$, recoberto por uma gramínea denominada puxa-tripa. Nos seus trechos mais difíceis, ocaminho chegava a ser pavimentado com pedras. Em alguns trechos era sinalizado por inscrições rupestres, mapas e símbolos astronômicos de origem indígena”. (p. 82)
}

A via peabiruana visava à facilidade de locomoção, não importando se esta se dava através de matas, serras, pântanos, terrenos pedregosos ou areais. Não importava se era uma trilha gramada, ou calçada com pedras ou simplesmente marcada com estacas. Muitas vezes, o caminho era sinalizado por rochas talhadas, ou seja, com marcos geodésico feitos em monólitos fincados no chão. Uma dessas pedras talhadas, um dos sinais de identidade do Peabiru, foi encontrada em Florianópolis. O achado foi feito pelo antropólogo Adnir Ramos e fica na ponta do Gravatá (Praia da Galheta).

A entrada do Peabiru na terra paraguaia se fazia por dois ramais. O primeiro era rio Mondaí-Assunção/rio Paraguai-Chaco. O segundo era rio Iguatemi-Alto Chaco-Porto Casado. Os dois ramais se juntavam no Chaco. O Peabiru, então, seguia o rio Paraguai ao norte até a serra de Santa Luzia.

Em Corumbá e Puerto Suarez, guinando a oeste, penetrava na Bolívia, passando por Cochabamba-Sucre-Potosí. Nesses locais existiam caminhos incas e era provavelmente ali que o Peabiru já se confundia com eles. A partir de Potosí, a estrada inca seguia pelo rio Desaguadero, ou por uma linha paralela mais ao norte. Alcançava depois o lago Titicaca, entrando no Peru. Contornava o lago pelo norte e sul. A bifurcação se unia em Cacha, voltando a ser uma via única.Essa via rumava para Cuzco, a capital incaica. A partir dali havia várias opções para alcançar o Pacífico. As mais próximas eram as trilhas para o litoral de Tacna, Moquegua e Arequipa.

Construído em geografia ideal, o Peabiru possibilitava a subida da serra catarinense com pequeno esforço.Partindo talvez do atual município de Palhoça (Massiambu) e Florianópolis, a trilha ia até Barra Velha, penetrando continente adentro no rumo do rio Itapocu..Passava provavelmente pelos atuais municípios de Jaraguá do Sul, Corupá e São Bento do Sul. Cruzava um rio que os índios chamavam de Iguaçu (Àgua Grande), entrando hoje no estado do Paraná. Passaram possivelmente pelas atuais cidades de Rio Negro, Campo do Tenente, Lapa, Porto Amazonas, Palmeira, Ponta Grossa e Castro. Aí o Peabiru tomava o rumo noroeste alcançando outro rio, chamado pelos indígenas de Tibagi. 
Dentro do estado do Paraná teria existido ainda outro ramal, proveniente do interior de São Paulo (que possivelmente foi usado pelos bandeirantes para capturar índios e destruir as missões jesuíticas) que percorria os seguintes municípios: Jardim Olinda, Itaguajé, Paranapoema, Paranacity, Cruzeiro do Sul, Uniflor, Atalaia, Mandaguaçu, Maringá, Floresta, Itambé, Engenheiro Beltrão, Peabiru e Campo Mourão. A partir de Campo Mourão haveria uma bifurcação, a partir da qual um ramo seguiria talvez por Farol, Janiópolis e Goioerê. E outro ramo que iria por Luiziana, Mamborê, Nova Cantu, Campina da Lagoa e Ubiratã.

A expedição de Aleixo Garcia passou pelo Peabiru na direção oeste, atravessando as cabeceiras dos rios Ivaí e Cantu. Cruzaram o alto Piquiri e, acompanhando sua margem esquerda, rumo oeste, alcançaram o grande rio Paraná, possivelmente perto de Guaíra, fronteira com o Paraguai. Este trecho englobaria talvez os seguintes municípios: Tibagi, Reserva, Cândido de Abreu, Boa Ventura de São Roque, Pitanga, Santa Maria do Oeste, Palmital, Laranjal, Diamante do Sul, Guaraniaçu, Campo Bonito, Bragancy, Iguatu, Corbélia, Anahy, Cafelândia, Nova Aurora, Iracema do Oeste, Jesuítas, Formosa do Oeste, Assis Chateaubriand, Palotina, Terra Roxa e Guaíra.

Esse roteiro foi repetido, muitos anos depois, pelo governador Cabeza de Vaca, com apenas uma diferença: Cabeza de Vaca chegou ao rio Paraná na altura da atual Foz do Iguaçu, e Aleixo o teria feito alguns quilômetros ao norte, por Guaíra.

O desvio feito por Cabeza de Vaca abrangeu possivelmente o seguinte trajeto: Tupãssi, Toledo, São Pedro do Iguaçu, Vera Cruz do Oeste, Ramilândia, Medianeira, Serranópolisdo Iguaçu, São Miguel do Iguaçu e Foz do Iguaçu. A coincidência (parcial) das rotas dos dois desbravadores acabou facilitando a reconstrução histórica da viagem do pioneiro Aleixo Garcia e foi mencionada por vários autores. Manuel Dominguez afirma que Cabeza de Vaca saiu da Ilha de Santa Catarina e alcançou o Paraguai "pelo caminho que Garcia tinha vindo". Nicolas delTecho diz que:

"Cabeza de Vaca seguiu por terra o caminho que antes havia levado Aleixo Garcia. O trajeto seguido por (Aleixo) Garcia demonstra seu amplo conhecimento da terra e ter ouvido bem os índios. Nenhuma rota melhor que a eleita por ele para avançar do Atlântico aos contrafortes andinos. Digamos que desde a costa...veio pela rota que 20 anos mais tarde seria seguida por ÁlvarNuñes”. (p. 106)

Alguns pesquisadores defendem que o caminho se estendia da fóz do rio Itapocu em sentido sul, margeando a costa catarinense ou próximo desta, até a Ilha de Santa Catarina e outros defendem que o caminho continuava mais ao sul após a Ilha de Santa Catarina até chegar à cidade de Laguna ou Mbiazá que já era conhecida também no século XVI.

A antropóloga e mestre em arqueologia, Deise Lucy M, da UFSC, considera possível a ocorrência de uma trilha indígena entre a Ilha de Santa Catarina e o Itapocu:

"Há probabilidade inclusive de que a construção de algumas parcelas da BR-101 entre Florianópolis e Barra Velha tenha aproveitado o leito de um antigo caminho indígena ali existente". (p. 94) 
O arqueólogo paranaense Igor Chmyz, na década de 1970, identificou cerca de trinta quilômetros remanescentes da trilha, na área rural de Campina da Lagoa, no estado do Paraná. Ao longo desse trecho, foram ainda identificados sítios arqueológicos com vestígios das habitações utilizadas, provavelmente, quando os indígenas estavam em trânsito.

Ele afirma que o itinerário do Caminho do Peabiru, tomando como base a expedição de Cabeza de Vaca, teriam entrado pela confluência da direita do rio Itapocuzinho margeando o caminho próximo deste mesmo rio e por ali o caminho seguiria subindo pelas beiradas das serras do rio Manso (já nos limites de Jaraguá do Sul com Campo Alegre e Joinville), dalí chegando no planalto e passando pelas localidades de Campos de São Miguel e Fragosos (limites de Campo Alegre com São Bento do Sul e também com o estado do Paraná), seguindo o caminho em direção ao rio Negro (chamado antigamente também de rio Iguaçu), cruzando o mesmo nesta região citada.

Esta teoria é defendida segundo o arqueólogo por causa da proximidade deste possível itinerário com uma formação rochosa na zona limítrofe de Joinville com Campo Alegre já nos altiplanos chamado popularmente de "Castelo dos Bugres" (próximo da estação hidrelétrica desativada do salto do rio Piraí e também com a SC-301 conhecida como estrada Dona Francisca), na qual antigamente segundo o arqueólogo este acidente geográfico era utilizado pelos índios como um local sagrado segundo suas crenças e lendas.

O mesmo arqueólogo tenta coincidir o nome dado ao rio Itapocu na sua etmologia (Ita=Pedra, poku=Grande) com uma povoação indígena que poderia ter existido na região naqueles tempos chamada de Itaguaçú que tem como significado "Lugar onde há Pedras Grandes".Esta teoria leva mais em conta a questão supostamente mística que envolve o Caminho do Peabiru do que os próprios relatos históricos que não relatam ou não condiz com o itinerário percorrido pelos desbravadores da coroa espanhola pelo vale do rio Itapocu.

A confluência do rio Humboldt com o rio Novo, ambos na cidade de Corupá. Dali nasce o nome "rio Itapocu", segundo dados hidrográficos do IBGE. Nesta confluência, foram encontradas pontas de flecha e pedras lascadas, além de alguns artefatos de cerâmica, comprovando que o local servia de alguma maneira de acampamento (provavelmente este local fora utilizado como descanso da jornada dos indígenas e também dos desbravadores da coroa espanhola do século XVI).

Próximo desta confluência, um pouco mais abaixo na margem esquerda do rio Itapocu, na localidade do bairro Santo Antônio em Jaraguá do Sul, similarmente foram encontrados alguns artefatos de cerâmica, pontas de flecha e pedras lascadas bem antigas. Isto mostra que o caminho a partir da entrada do vale do Itapocu, poderia ter sido feito pela margem esquerda do rio.

No meio da confluência dos rios Novos e Humboldt, o Caminho do Peabiru continuava somente por terra (uma boa parte ocupada a partir da ponte férrea de Corupá e a atual avenida Getúlio Vargas, indo a trilha em direção ao cume da serra onde circunda o rio dos Bugres (afluente do rio Vermelho). Dalí o caminho beirava o rio Banhados no seu médio curso entre São Bento do Sul e Rio Negrinho. 
Alguns mapas feitos no final do século XVI e XVII, se encontram algumas nomenclaturas referentes a bacia hidrográfica do rio Itapocu que também era conhecidos pelos topônimos e corruptelas de "Ytabucu (Ytabucú), Ytabuca, Yrabuco, Ytabusú, Itabuzú, Ytabucó, Itabuco, Itabucu (Itabucú), Itabuca, Itacumbu, Tabucá, Tapuca (Tapucá), Tabuen, Tabucú, Itaburu (Itáburu), Itabicu, Itapicu, Itapucuru, Itapogú, Ipuaçú, Itapecu, Itacumbu, Y Tanunço, Itapuen e Itapuan.

Há uma hipótese de que o caminho fosse através do Monte Crista em Garuva, contudo, este esbarra com uma dificuldade advinda da natureza da região. A subida do monte exigia (como ainda hoje exige) uma escalada de muito esforço. Nem mesmo a existência de uma escadaria antiga, feita de pedras, anula o cansaço do viajante. Embora jornais, revistas, livros e programas de televisão venham dizendo, com frequência, que a obra poderia ser de origem inca, pertencente ao complexo do Peabiru, infelizmente não há, até o momento, qualquer evidência histórica ou arqueológica que dê sustento a essa versão.

A informação do cacique WeráTupã em depoimento à Rosana Bond (p. 100) em abril de 2004, diz:

\begin{abstract}
"O caminho mesmo era pelo rio Itapocu que ele entrava. Não era pelo Monte Crista e pelo Quiriri. Mas eles (os guaranis antigos) iam visitar estes lugares (Monte Crista e Serra do Quiriri). Porque ali tinha um pajé muito poderoso e iluminado. Subiam ali para conversar com ele. A gente acredita que esse pajé fez a casa da reza (opy) lá em cima. Os pajés gostavam dos lugares altos para fazer a casa de reza porque assim o contato com os espíritos era melhor. O caminho (do Peabiru) era igual à uma estrada grande, como exemplo a BR-101. Mas tinha outros caminhos pequenos que ligavam. Lá no Quiriri era um caminho desses, menor, não era para andar toda hora. Só alguns que iam lá, para falar com o pajé”.
\end{abstract}

Ou seja, o cacique confirma que o trecho principal do Peabiru, entrava pelo Itapocu, conforme os relatos do século XVI. Mas acrescenta um interessante dado novo: a existência de um ramal, tido como sagrado, que era conhecido e praticado apenas por alguns escolhidos, nas áreas de Garuva.

\title{
5 CONSIDERAÇÕES FINAIS
}

A cada dia novas descobertas históricas e arqueológicas vêm comprovar o respeitável grau de conhecimento dos povos nativos do Brasil e da América do Sul. Ajudando a desmoronar a versão dos invasores brancos de que a civilização chegou ás terras americanas com os europeus, e que os indígenas desta parte chamada "Novo Mundo" (à exceção dos Incas e outras poucas tribos) eram selvagens e sua cultura, inferior.

Um desses grandes feitos indígenas pré-colombianos, infelizmente pouco conhecido dos brasileiros, é o Caminho de Peabiru. Com mais de três mil quilômetros, o Peabiru foi a estrada transcontinental mais importante da América do Sul antes da chegada dos europeus. Ele ligava os Andes ao oceano Atlântico, servindo como ligação entre os nossos guaranis e 
os demais povos sul-americanos. Fascinante, misterioso, polêmico, tido como sagrado, o Caminho unia o litoral de Santa Catarina e São Paulo ao grande império inca no Peru.

Além de ser uma obra viária de grande competência, a existência do Peabiru revela, entre outras coisas, que os índios do sul do Brasil, ao contrário do que comumente se pensa, dominavam um conjunto de informações geográficas sofisticadas.

\section{REFERÊNCIAS}

BOND, Rosana.A Saga de Aleixo Garcia - O Descobridor do Império Inca. Rio de Janeiro:Coedita, 2004, p. 73, p. 82, p. 91, p. 94, p. 100, p.106

CRUZ, Josefina. DoñaMencialaAdelantada. Assunção: Litocolor, 1998, p. 171.

SANABRIA, Hernando. Nuflo de Chavez - El Caballero de Andante de la Selva. La Paz: Juventud, 1984, p. 43.

VACA, Cabeza de. Naufrágios e Comentários - Prefácio de Henry Miller - Introdução de Eduardo Bueno. Santa Maria: Pallotti,1999, Vol. 155.

http://peabirucatarinense.blogspot.com.br/ - acesso em 25 de abril de 2013. 